\title{
FÓRUM DA PAISAGEM: PAISAGENS DA RESISTÊNCIA
}

\author{
Euler Sandeville Júnior \\ Fany Cutcher Galender
}

$\frac{\text { I64 }}{\text { ì }}$

Exposição de Roberto

Crédito: Euler Sandeville Jr.

No dia 17 de maio de 2005, foi realizado na FAU - Cidade Universitária o Fórum da Paisagem, com o tema "Paisagens da resistência", promovido pelo Laboratório Gestão e Projeto do Espaço e organizado pelo Prof. Dr. Euler Sandeville Júnior. $\mathrm{O}$ intuito foi apresentar e discutir questões referentes à produção das paisagens urbana e rural latino-americanas, em diferentes momentos históricos e contextos sociais de resistência. O evento foi aberto aos alunos da graduação, da pósgraduação e ao público em geral. O fórum se prendia muito à vivência da paisagem e dos fatos em questão, valorizando experiências diferentes como base para o debate, trazendo um convidado que atuou, efetivamente, em um movimento revolucionário uruguaio, um professor universitário o qual, a par de sua militância, olha a partir de uma pesquisa para um ambiente revolucionário contemporâneo no México, e um arquiteto paisagista que projeta para um expressivo movimento social brasileiro.

A primeira exposição teve o título "Paisagem Urbana e o Movimento Tupamaro no Uruguai nas Décadas de 60 e 70", apresentada por Roberto Bonino, militante nesse movimento e atualmente radicado no Brasil. O movimento tupamaro uruguaio atingiu seu apogeu na década de 70 do século passado, caracterizando-se pela ação de um grupo de militantes que congregava pessoas de diferentes matizes ideológicos de esquerda, sob a égide de um contexto revolucionário o qual agitava, então, não só a América Latina, mas também a Europa (sobretudo França e Alemanha) e os Estados Unidos. Eram, entretanto, díspares esses movimentos contestatórios de operários, estudantes, grupos contrários à Guerra do Vietnã, entre

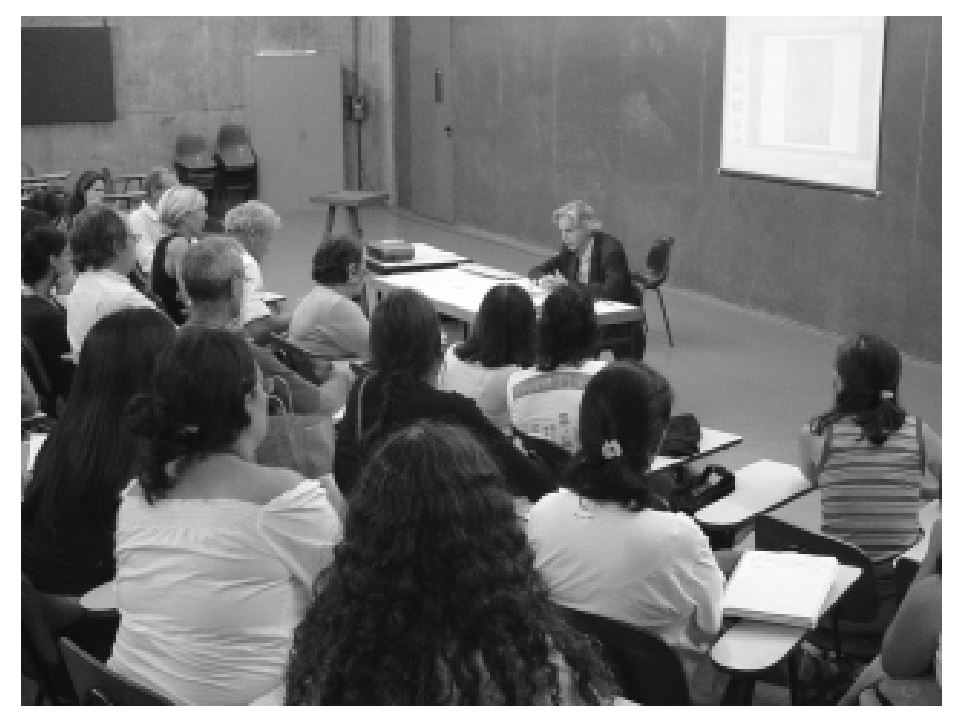


Exposição de Philip Gunn Crédito: Euler Sandeville Jr.

outros, e que marcaram um intenso momento cultural e de inquietações sociais em torno dos anos 60 e 70.

O movimento uruguaio se pauta, inicialmente, por procurar combater a corrupção empresarial dos grandes conglomerados econômicos implantados no país. Paralelamente ao ingresso de novos participantes e ao acirramento das condições políticas do país, o grupo reformula suas metas, visando atuar em prol da queda da ditadura que se implantava com forte apoio externo, como se verificou, simultaneamente, nos outros vizinhos do Cone Sul.

Roberto Bonino, então sindicalista residente em Montevidéu e que participou da fundação do movimento tupamaro, relatou sua experiência desde a formação do grupo, no final dos anos 50 até seu desmantelamento em 1973, no auge da ditadura uruguaia. Narrou as diferentes ações e atividades realizadas, ressaltando a eficiente organização interna do movimento e a alta capacitação de seus militantes, por meio de treinamentos intensivos em diversos países.

A plácida paisagem urbana de Montevidéu encobriu uma efervescente dinâmica paralela ao cotidiano da cidade, onde oficinas mecânicas, gráficas clandestinas e, até mesmo hospitais, serviam aos propósitos do grupo, ocultandose na paisagem e tecendo uma rede invisível de ações. Essa mobilização e infraestrutura não eram percebidas pela maioria de seus habitantes, senão a partir das ações tupamaras.

Apesar desse intenso preparo e da firmeza das intenções da militância, o movimento foi extinto pelos militares, com a prisão e exílio de grande parte de seus componentes, deixando ensinamentos e questões para reflexões das gerações futuras, não só com relação à construção da cidadania e da luta pela liberdade. 0 depoimento de Roberto Bonino aponta também para uma profunda reflexão humana sobre os limites dessa luta, de seu campo ético e não só de batalha, em um contexto de extrema pressão e sentimento de urgência, em que a sobrevivência dependia da clandestinidade.

A segunda abordagem, com o título "A Paisagem Rural dos Assentamentos Zapatistas no México", foi feita pelo Prof. Dr. Phillip Gunn, da FAUUSP, arquiteto

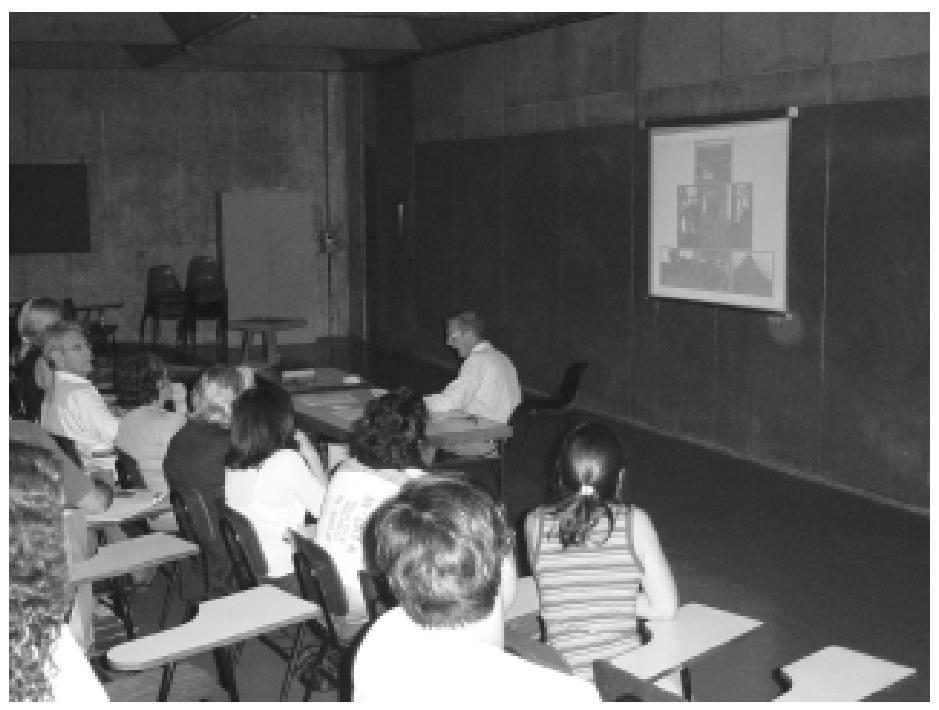


irlandês que vive no Brasil há 25 anos. De origem católica e militante de esquerda desde a juventude, relatou sua formação e suas atividades de militância junto de movimentos de resistência, especialmente o Exército Revolucionário Irlandês (IRA).

Discorreu sobre sua atuação com diferentes grupos e movimentos sociais, focando sua exposição no movimento zapatista mexicano, com o qual entra em contato em 1997. Esse movimento de base indígena e agrária tem longa história de luta contra o latifúndio e as oligarquias locais desde o período colonial.

Gunn ressaltou a sobrevivência cultural da sociedade indígena diante da dominação colonial e seu processo de adaptação às novas organizações religiosa, social e econômica, impostas pela corte espanhola, apresentando também um painel das intensas lutas camponesas pela posse da terra, destacando a atuação de Emiliano Zapata e Pancho Villa e as formas de divisão fundiária e da produção agrícola que se instauram no México.

$\mathrm{Na}$ década de 80, novas experiências agrárias são consolidadas no estado de Puebla, com o surgimento de cooperativas voltadas para o desenvolvimento sustentável e a capacitação profissional, pautadas pelo destaque na participação feminina na definição dos rumos de produção dessas comunidades.

Em Chiapas, ao Sul do México, surge o Exército Zapatista de Libertação Nacional (EZLN) que, pela luta armada, estabelece o combate aos efeitos do neoliberalismo global e reafirma os direitos indígenas. O grupo se caracteriza pelo uso intensivo da internet para divulgação de suas propostas e ações, além de propor novas formas de organização política e social dentro dos assentamentos, revendo o sistema de representação e de produção.

A última exposição, "Paisagem e Movimento Social: O Projeto e Implementação da Escola Rural do Movimento dos Sem-Terra (MST) em Guararema, SP", coube ao arquiteto paisagista Raul Pereira, o qual cursou a FAUUSP de 1969 a 1975, vindo do interior do estado de São Paulo para a

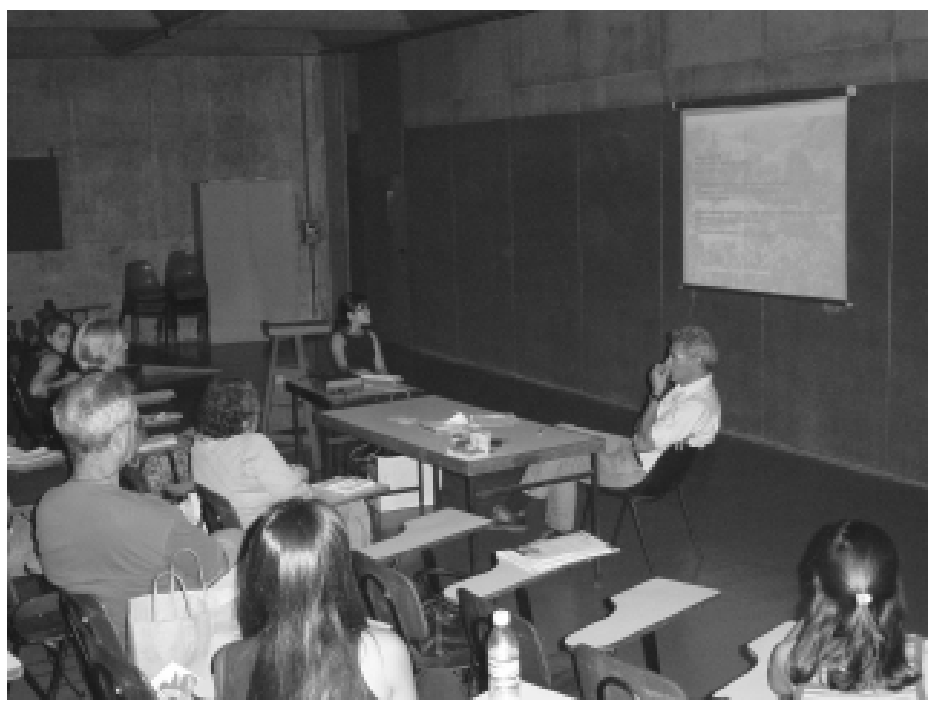


capital, nos anos de forte agitação política e social no Brasil. Atualmente, é mestrando no curso de pós-graduação da FAU e desenvolve, em seu escritório, trabalhos pautados por uma preocupação social, além de outros mais corriqueiros do campo de trabalho em paisagismo.

Ao entrar em contato, no início dos anos 70, com as polêmicas travadas entre diferentes grupos na escola, aderiu ao de Sérgio Ferro, impressionado pela abordagem relativa à produção do projeto perante as condições do trabalho da mão-de-obra da construção civil.

Essa permanente inquietação com a dificuldade de superação da falta de perspectiva de mudança socioeconômica, levou-o a participar, mais recentemente, de atividades junto do Movimento dos Sem Terra (MST), que surge na região paulista do Pontal do Paranapanema, extremo oeste do estado, reivindicando uma mudança estrutural nas relações de produção no campo e nas relações socioeconômicas a envolverem toda a sociedade brasileira.

Raul participou da criação da Escola Nacional Florestan Fernandes, em Guararema, desenvolvendo um trabalho para um local de construção e divulgação do conhecimento que atendesse as demandas dessa população ligada ao campo, porém participante do mundo globalizado.

O projeto de paisagismo desenvolvido caracterizou-se pela intensa participação dos usuários, que, curiosamente, possuem uma antiga e particular relação com a terra e a vegetação. Sob a égide das diferentes leituras e perspectivas, nasceu um projeto no qual diversas vivências se mesclaram.

A força dessas experiências mostrou-nos que novas formas de pensamento podem orientar o cotidiano das populações latino-americanas, ampliando a diversidade de possibilidades de paisagens e de vida, em cada contexto específico. Nesses casos, a paisagem, lugar da vida e da experiência cotidiana, torna-se o palco de uma intensa luta pela vida, abandonando os meios instituídos e postulando uma atitude de resistência que se coloca em antagonismo a processos que se fazem sentir no cotidiano e no lugar, mas cujas causas estão em uma ordem mais geral e menos explícita, mas nem por isso invisível.

A fala dos três convidados suscitou um debate entre os presentes, que percorreu o conjunto de temas tratados, polemizando em várias questões, não em busca de uma novidade, pois são questões recorrentes em uma série de espaços de discussão, mas como um momento de reflexão o qual emergiu a partir da experiência de cada convidado.

Destacamos alguns dos temas de discussão: a mobilidade no espaço em contraposição à necessidade de estruturas fixas de apoio, que ocorre de modos diferentes nos três movimentos abordados; a dependência, no caso do movimento zapatista, de estruturas tecnológicas e de mercado, seja a internet para organização e militância do movimento, seja do mercado formal e informal para colocação de seus produtos; condições de trabalho na terra e na cidade, da ausência de estruturas de apoio ao trabalho e da escola pensada de um modo homogeneizador, com dificuldades de reconhecer modelos e relações diferentes do ensino no campo e na cidade; do papel do intelectual em sua relação com a sociedade como um ponto central a ser pensado; de uma série de circunstâncias que, mesmo fora de um contexto de resistência e revolução, acabam ficando invisíveis na paisagem e tratadas como marginais, periféricas 
ou problemáticas, sem reconhecimento de sua especificidade e profunda integração na vida urbana; a relação entre projeto e paisagem em seu contexto cultural, bem como a participação do usuário na definição do programa e do projeto.

\section{Euler Sandeville Júnior}

Doutor pela FAUUSP, professor no curso de graduação e professor orientador no Programa de Pós-Graduação Interunidades em Ciência Ambiental (PROCAM/USP). Coordenador da área de concentração Paisagem e Ambiente, do Programa de PósGraduação em Arquitetura e Urbanismo da FAUUSP, coordenador do Laboratório Gestão e Projeto do Espaço, e membro, respectivamente, da CPG-FAUUSP e da CPGPROCAM.

\section{Fany Cutcher Galender}

Arquiteta pela Universidade Mackenzie, professora dos cursos de atualização "Paisagismo: Concepção e Projeto I e II", promovidos pela Fundação para a Pesquisa Ambiental (FUPAM), arquiteta titular do Escritório Fany Galender Arquitetura e Paisagismo S/C Ltda. Arquiteta do Departamento de Parques e Áreas Verdes (Depave), da Secretaria Municipal do Verde e Meio Ambiente da Prefeitura de São Paulo, comissionada no Departamento de Projetos / Grupo de Disciplinas Paisagem Ambiente (GDPA) da FAUUSP, desenvolvendo pesquisas junto dos laboratórios QUAPÁ (Quadro do Paisagismo Brasileiro) e LABPARC (Laboratório Paisagem, Arte e Cultura). 